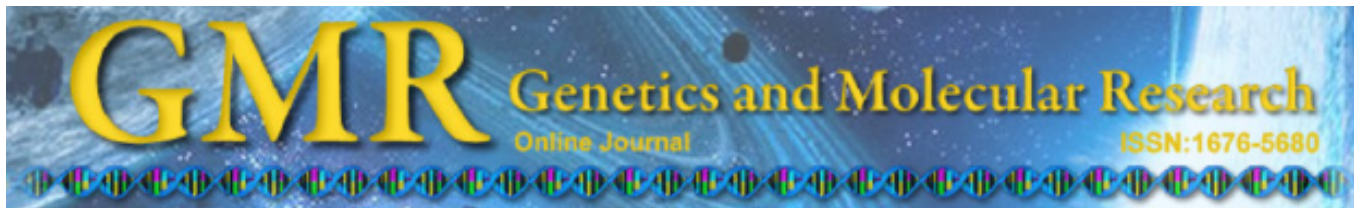

\title{
Ala-9Val polymorphism of Mn-SOD gene in sickle cell anemia
}

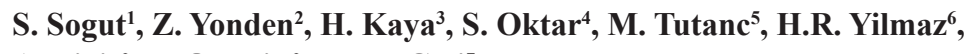
A. Yigit ${ }^{6}$ N. Ozcelik ${ }^{6}$ and E. Gali ${ }^{7}$

${ }^{1}$ Department of Biochemistry,

Medical Faculty of Bezmialem Vakif University, İstanbul, Turkey

${ }^{2}$ Department of Biochemistry,

Medical Faculty of Mustafa Kemal University, Hatay, Turkey

${ }^{3}$ Hematology Division of Internal Medicine,

Medical Faculty of Mustafa Kemal University, Hatay, Turkey

${ }^{4}$ Department of Pharmacology,

Medical Faculty of Mustafa Kemal University, Hatay, Turkey

${ }^{5}$ Department of Pediatrics,

Medical Faculty of Mustafa Kemal University, Hatay, Turkey

${ }^{6}$ Department of Medical Biology,

Medical Faculty of Süleyman Demirel University, Isparta, Turkey

${ }^{7}$ Center for Hemoglobinopathy Diagnosis and Treatment,

Antakya Public Hospital, Hatay, Turkey

Corresponding author: S. Sogut

E-mail: sadiksogut2@hotmail.com

Genet. Mol. Res. 10 (2): 828-833 (2011)

Received October 14, 2010

Accepted January 4, 2011

Published May 10, 2011

DOI 10.4238/vol10-2gmr1106

ABSTRACT. Oxidative stress may be contributory to the pathophysiology of the abnormalities that underlie the clinical course of sickle cell anemia. We looked for a possible genetic association between the functional polymorphism Ala-9Val in the human Mn-SOD gene and sickle cell anemia. One hundred and twenty-seven patients with sickle cell anemia and 127 healthy controls were recruited into the study. Alanine versus valine polymorphism in the signal peptide of 
the Mn-SOD gene was evaluated using a primer pair to amplify a 107-bp fragment followed by digestion with the restriction enzyme NgoMIV. In the sickle cell anemia patients, the frequency of $\mathrm{Val} / \mathrm{Val}$ genotype was approximately 1.4 -fold lower and that of Ala/Val was 1.3 -fold higher compared to the controls. No significant difference in genotype frequencies was found between patients and controls $\left(\chi^{2}=\right.$ 4.561 , d.f. $=2, \mathrm{P}=0.101)$. The Val-9 was the most common allele in patient and healthy subjects. No significant difference in allele frequencies was found between patients and controls $\left(\chi^{2}=1.496\right.$, d.f. $=$ $1, \mathrm{P}=0.221)$. We conclude that the Mn-SOD gene polymorphism is not associated with sickle cell anemia.

Key words: Sickle cell anemia; Superoxide dismutase; Polymorphism; Oxidative stress

\section{INTRODUCTION}

Sickle cell anemia (SCA) is a hereditary disorder, caused by a substitution of valine for glutamic acid at the $\beta-6$ position in the hemoglobin $(\mathrm{Hb}) \beta$-chain, with higher potential for oxidative damage due to chronic redox imbalance in red cells. The formation of this new $\mathrm{Hb}$ type $(\mathrm{HbS})$ in SCA may alter the delicate balance of free-radical generation and antioxidant defense systems in red blood cells, which are a significant source of free radicals in biological systems. It has been recently shown that SCA patients have significantly higher glutathione peroxidase (GPx) and superoxide dismutase (SOD) activities than do healthy controls (Manfredini et al., 2008). SODs, including Cu-, Zn- and Mn-SOD and extracellular $\mathrm{SOD}$, are protective enzymes against oxidative stress. They can specifically scavenge $\mathrm{O}_{2}-$ by catalyzing its dismutation to hydrogen peroxide and molecular oxygen. Mn-SOD, which is a mitochondrial form of SOD, is involved in controlling dioxygen toxicity in the mitochondrion, an organelle of extreme oxidative load (Sanders et al., 1995). Fridovich (1995) found a structural mutation of $\mathrm{T}$ to $\mathrm{C}$ substitution in the coding sequence of Mn-SOD gene, which changes the amino acid codon at -9 position in the signal peptide from valine (GTT) to alanine (GCT). This signal peptide is removed during processing to a mature enzyme and plays a key role in targeting the enzyme to the mitochondria. Oxidative stress plays a role in the pathophysiology of the clinical manifestations of the disease, and this may be contributory to the pathophysiology of the abnormalities that underlie the clinical course of SCA (Schacter et al., 1988).

The present study aimed to assess whether there is a genetic association between a functional polymorphism (Ala-9Val) in the human Mn-SOD gene and sickle cell anemia.

\section{MATERIAL AND METHODS}

The study was performed in accordance with the Declaration of Helsinki. The project was carried out with the approval of the medical human Ethics Committee of the Mustafa Kemal University Faculty of Medicine, and all participants and/or their parents gave informed consent. 


\section{Patients}

The patients with sickle cell anemia were referred to the Center for Hemoglobinopathy Diagnosis and Treatment of Antakya Public Hospital. Clinical as well as demographic data were obtained from medical records and interviews with the patients or their parents. A total of 127 patients ( 44 boys and 83 girls) with SCA were recruited with ages ranging from 3 to 34 years (mean \pm SD: $17.2 \pm 8.8$ years). None of the subjects had any other chronic diseases. Control individuals were selected from those systemically healthy subjects who had no blood disorders. Thus, a total of 127 children were recruited as controls ( 66 boys and 61 girls) with ages ranging from 2 to 40 years (mean: $16.2 \pm 9.2$ years). Informed consent was obtained from all subjects and/or their parents.

\section{Methods}

Venous blood samples, collected in EDTA, were obtained during routine blood sampling for biochemical and hematological analyses from patients and controls. Genomic DNA was isolated from venous blood using the Promega DNA isolation kit (Madison, WI, USA) according to manufacturer recommendations. An alanine/valine polymorphism in the signal peptide of Mn-SOD gene was evaluated using a primer pair (forward 5'AC CAGCAGGCAGCTGGCGCCGG3' and reverse 5'GCGTTGATGTGAGGTTCCAG3') as defined by Mitrunen et al. (2001) to amplify a 107-bp fragment. Polymerase chain reaction (PCR) amplification of the genomic DNA was performed as described by Akyol et al. (2004) in a total volume of $50 \mu \mathrm{L}$, containing $50 \mathrm{ng}$ genomic DNA, $20 \mathrm{pmol} / \mu \mathrm{L}$ of each primer, $1.25 \mathrm{U}$ Taq polymerase (in $50 \mathrm{mM}$ Tris-Cl, $\mathrm{pH} 8.0,100 \mathrm{mM} \mathrm{NaCl}, 0.1 \mathrm{mM}$ EDTA, $1 \mathrm{mM}$ DTT, $50 \%$ glycerol and $1 \%$ Triton X-100), $2 \mathrm{mM}$ dNTP, $2 \mathrm{mM} \mathrm{MgCl}_{2}, 1 \mathrm{X}$ PCR buffer containing $50 \mathrm{mM} \mathrm{KCl}, 10 \mathrm{mM}$ Tris- $\mathrm{HCl}, \mathrm{pH} 8.3$, at $25^{\circ} \mathrm{C}$. PCR conditions involved an initial denaturation of DNA at $95^{\circ} \mathrm{C}$ for $5 \mathrm{~min}$, followed by 35 cycles of amplification at $95^{\circ} \mathrm{C}$ for $1 \mathrm{~min}$ (melting), $61^{\circ} \mathrm{C}$ for $1 \mathrm{~min}$ (annealing), and $72^{\circ} \mathrm{C}$ for $2 \mathrm{~min}$, and a final extension at $72^{\circ} \mathrm{C}$ for $7 \mathrm{~min}$. The resulting 107-bp PCR product was digested with the restriction

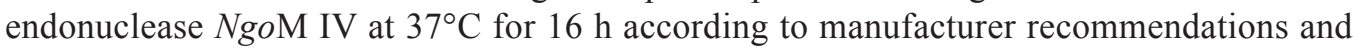
digestion products were analyzed following electrophoresis on $3 \%$ agarose gel stained with ethidium bromide $(0.5 \mu \mathrm{g} / \mathrm{mL})$. Restriction enzyme digestion results in a 107-bp product (allele 1 Val-9) or 89- and 18-bp products (allele 2 Ala-9).

\section{Statistical analysis}

All statistical analyses were performed using the SPSS version 15.0 for Windows (SPSS Inc., Chicago, IL, USA). Differences in the demographic characteristics of the patients were assessed between the three Mn-SOD genotypes using one-way analysis of variance. The chi-square goodness-of-fit test was used to test the distribution of genotypes and allele frequencies for deviations from Hardy-Weinberg equilibrium. Chi-square was used to compare allele and genotype frequencies between the patients and the controls. Differences in allelic distribution between patients and controls, as well as between patient subgroups, were analyzed using the Fisher exact test. 


\section{RESULTS}

Allele and genotype frequencies of the subjects for the Ala-9Val polymorphism in the Mn-SOD gene are shown in Table 1. The genotypic distributions in patients and normal controls were consistent with the Hardy-Weinberg equilibrium. If the 9 codon is GCT (Ala), then digestion with $\mathrm{NgoM}$ IV produces two DNA fragments, 89 and 18 bp in length. If the codon is GTT (Val), the amplified product is not digested with NgoM IV and remains as a whole 107bp DNA fragment.

Table 1. The genotypes of Ala-9Val polymorphism and allele frequencies in controls and sickle cell anemia patients.

\begin{tabular}{|c|c|c|c|c|c|}
\hline & \multicolumn{3}{|c|}{ Genotypes $^{\mathrm{a}}$} & \multicolumn{2}{|c|}{ Allele frequencies ${ }^{\mathrm{b}}$} \\
\hline & $\mathrm{Val} / \mathrm{Val}$ & Val/Ala & Ala/Ala & $-9 \mathrm{Val}$ & -9 Ala \\
\hline Sickle cell anemia $(\mathrm{N}=127)$ & $49(38.6 \%)$ & $66(52.0 \%)$ & $12(9.4 \%)$ & 0.65 & 0.35 \\
\hline Control (N = 127) & $65(51.2 \%)$ & $55(43.3 \%)$ & $7(5.5 \%)$ & 0.73 & 0.27 \\
\hline
\end{tabular}

Data are reported as number with percent in parentheses. ${ }^{a}$ No significant difference in genotype frequencies between patients and controls $\left(\chi^{2}=4.561\right.$, d.f. $\left.=2, P=0.101\right)$. The genotypic distributions in both patients and controls were within the Hardy-Weinberg equilibrium. ${ }^{b}$ No significant difference in allele frequencies between patients and controls.

The genotype was available from 127 patients and 127 controls. A similar distribution of genotypes has been observed in the patient group compared to the group of healthy subjects (Table 1). In the sickle cell anemia patients, the frequency of the Val/Val genotype was approximately 1.4 -fold lower and that of Ala/Val was 1.3 -fold higher compared to the controls. No significant difference in genotype frequencies was found between patients and controls $\left(\chi^{2}\right.$ $=4.561$, d.f. $=2, \mathrm{P}=0.101)$. The Val-9 was the most common allele in patient and healthy subjects. No significant difference in allele frequencies was found between patients and controls $\left(\chi^{2}=1.496\right.$, d.f. $\left.=1, P=0.221\right)$.

\section{DISCUSSION}

The aim of this study was to investigate the clinical relevance of functional Mn-SOD polymorphism in SCA. This study did not, however, reveal any significant association between the Ala-9Val polymorphism of Mn-SOD gene and SCA. Red blood cells with abnormal hemoglobin are frequently associated with increased hemoglobin autoxidation, iron accumulation in membranes, increased membrane damage, and a shorter red blood cell life span, but the mechanisms for many of these changes have yet not been elucidated.

SCA is a disorder of red blood cells, which are a significant source of free radicals. There is an integrated network of the antioxidant system, consisting of many enzymes such as SOD, which help to temper oxidative stress and injury to the red cell and tissues in general. It has been shown in a human study group that the SOD activity is lower in SCA patients than in controls and that the enzyme activity is inversely proportional to the degree of symptom severity (Schacter et al., 1985). Schacter et al. demonstrated that SCA patients with more severe 
manifestations had lower levels of SOD activity compared to those with milder symptoms but had the same amount of enzyme protein. Additionally, individuals with the sickle trait had amounts and activities of SOD comparable to black controls (Schacter et al., 1988).

In light of these studies, we hypothesized in the present study that a polymorphism in the squence of an important antioxidant enzyme, Mn-SOD, may influence the biological behavior of this enzyme and therefore the clinical diversity of SCA. To our knowledge, this is the first study that reports the potential role of functional SOD polymorphism in the pathogenesis of SCA. Several studies of the role of oxidative stress in pathogenesis evaluated Mn-SOD polymorphism, and finally a relationship in this gene polymorphism was disclosed (Akyol et al., 2005; Fujimoto et al., 2010). In addition, Costa et al. (2005) have shown that the G-463A myeloperoxidase polymorphism may be a significant genetic modulator that renders SCA patients more susceptible to infection.

Our study did not reveal any statistically significant correlations between Ala-9Val polymorphism of Mn-SOD gene and SCA. However, we observed that the Ala/Ala genotype was less frequent than the other genotypes (38.6 vs 51.2 for patients $v s$ control). Our results suggest that Mn-SOD is not associated with the physiopathology of SCA. Genetic variation in other reactive oxygen species (ROS) defense genes and ROS-producing genes could be important modifiers in the relationship of Mn-SOD with SCA. Other antioxidant enzymes such as GPx, catalase, and glutathione-S-transferase, as well as oxidant enzymes such as xanthine oxidase and myeloperoxidase as candidates for oxidant/antioxidant imbalance in SCA should thus be taken into account in future studies. Analyses in conjunction with other ROS-related polymorphisms will help to fully elucidate the contribution of these genes to SCA. For a greater understanding of the pathogenesis of SCA, larger studies are needed to evaluate whether any variant of the Mn-SOD gene contributes to the disease. A basic understanding about the expression and regulation of antioxidant enzymes in SCA is necessary to develop therapeutic interventions to control oxidative stress. Also, further investigations are warranted in larger populations with other antioxidant enzymes including copper- and zinc-containing SOD, extracellular SOD, GPx, and glutathione-S-transferases, as the underlying cause of SCA. The above future studies would shed further light on the management algorithms of SCA, whether to include antioxidant augmentation or dietary supplement of antioxidants.

\section{REFERENCES}

Akyol O, Canatan H, Yilmaz HR, Yuce H, et al. (2004). PCR/RFLP-based cost-effective identification of SOD2 signal (leader) sequence polymorphism (Ala-9Val) using NgoM IV: a detailed methodological approach. Clin. Chim. Acta 345: 151-159.

Akyol O, Yanik M, Elyas H, Namli M, et al. (2005). Association between Ala-9Val polymorphism of Mn-SOD gene and schizophrenia. Prog. Neuropsychopharmacol. Biol. Psychiatry 29: 123-131.

Costa RN, Conran N, Albuquerque DM, Soares PH, et al. (2005). Association of the G-463A myeloperoxidase polymorphism with infection in sickle cell anemia. Haematologica 90: 977-979.

Fridovich I (1995). Superoxide radical and superoxide dismutases. Annu. Rev. Biochem. 64: 97-112.

Fujimoto H, Kobayashi H, Ogasawara K, Yamakado M, et al. (2010). Association of the manganese superoxide dismutase polymorphism with vasospastic angina pectoris. J. Cardiol. 55: 205-210.

Manfredini V, Lazzaretti LL, Griebeler IH, Santin AP, et al. (2008). Blood antioxidant parameters in sickle cell anemia patients in steady state. J. Natl. Med. Assoc. 100: 897-902.

Mitrunen K, Sillanpaa P, Kataja V, Eskelinen M, et al. (2001). Association between manganese superoxide dismutase (MnSOD) gene polymorphism and breast cancer risk. Carcinogenesis 22: 827-829.

Sanders SP, Zweier JL, Harrison SJ, Trush MA, et al. (1995). Spontaneous oxygen radical production at sites of antigen 
challenge in allergic subjects. Am. J. Respir. Crit. Care Med. 151: 1725-1733.

Schacter LP, DelVillano BC, Gordon EM and Klein BL (1985). Red cell superoxide dismutase and sickle cell anemia symptom severity. Am. J. Hematol. 19: 137-144.

Schacter L, Warth JA, Gordon EM, Prasad A, et al. (1988). Altered amount and activity of superoxide dismutase in sickle cell anemia. FASEB J. 2: 237-243. 